Research Paper: PM-Power and Machinery

\title{
A genetic input selection methodology for identification of the cleaning process on a combine harvester, Part II: Selection of relevant input variables for identification of material other than grain (MOG) content in the grain bin
}

\author{
Geert Craessaerts $^{a, *}$, Wouter Saeys ${ }^{a}$, Bart Missotten ${ }^{b}$, Josse De Baerdemaeker ${ }^{a}$ \\ ${ }^{a}$ Department of Biosystems, Katholieke Universiteit Leuven, Kasteelpark Arenberg 30, B-3001 Leuven, Belgium \\ ${ }^{\mathrm{b}} \mathrm{CNH}$ Belgium N.V., Leon Claeysstraat 3A, B-8210 Zedelgem, Belgium
}

\section{A R T I C L E I N F O}

Article history:

Received 14 January 2007

Accepted 18 July 2007

Available online 24 October 2007
The cleaning process on a combine harvester is a complex process that is influenced by a wide range of parameters such as machine settings, field and crop-related parameters, etc. Because of the high time pressures combine drivers have to deal with, optimal settings for the cleaning section are usually only estimated once for each crop. As a consequence, differences in temporal and site-specific conditions are neglected. No recent literature is available that considers the interaction between the settings of the cleaning section (like e.g. fan speed, lower sieve opening and upper sieve opening) and the material other than grain (MOG) content in the grain bin, which is, however, an important performance parameter of the cleaning shoe.

In this study, a combine harvester was equipped with extra sensors that could contain valuable information necessary to predict the performance of the cleaning section. A nonlinear genetic polynomial regression technique was used to rank the pool of potential sensors as possible regression variables for a prediction model of the MOG content in the grain bin. This model is important for the automation of the cleaning shoe. Results showed that the MOG content in the grain bin is influenced non-linearly by differences in the amount of biomass on the sieve section and the fan speed, which are also correlated with each other.

c) 2007 IAgrE. Published by Elsevier Ltd. All rights reserved.

\section{Introduction}

The process of grain harvesting can be described as recovering grains from the field and separating them from the rest of the crop material (material other than grain, 'MOG') with a minimum grain loss and a predefined quality level of the end product (grain kernels in the grain bin). The entire harvesting process may be divided into cutting, threshing, separation and cleaning functions. This study will focus on the cleaning mechanism of a combine harvester. Cleaning refers to the final separation of grain from other crop material, which consists mainly of chaff and small straw pieces. The performance of a cleaning shoe can be expressed in terms of (1) grain losses, (2) cleaner capacity and (3) grain purity in the grain bin. The cleaning shoe performance is determined by a number of factors like (1) design factors such as sieve

*Corresponding author. Tel.: +3216 321444; fax: +3216328590

E-mail address: Geert.Craessaerts@biw.kuleuven.be (G. Craessaerts).

1537-5110/\$ - see front matter ( 2007 IAgrE. Published by Elsevier Ltd. All rights reserved.

doi:10.1016/j.biosystemseng.2007.07.002 
size, oscillation amplitude and frequency, (2) operating conditions including material feed-rate, cleaning shoe slope, airflow and sieve openings, and (3) crop properties including grain to MOG ratio, chaff and grain moisture, kernel dimensions, etc.

New design prototypes for the cleaning shoe were published by Hubner (1997) and Rothaug et al. (2003). Hubner (1997) introduced a rotary cleaning unit while Rothaug et al. (1999) investigated a circular oscillating grain cleaning unit and compared it with a standard linear oscillating cleaning section. As cited in Srivastava et al. (2006), research was investigated on determining the influence of the lip angles on the cleaning shoe performance and design factors like oscillation frequency and air volume were optimised. Srivastava et al. (2006) determined that the cleaning losses increase with MOG feed-rate and with grain/straw ratio. Böttinger and Kutzbach (1987) reported on the effect of fan speed and feed rate on the sieve losses. A more physical interpretation of the cleaning process is given in Miu (2003). Miu (2003) introduced a mathematical model of grain segregation and separation over the sieve length. The theory points out a bi-dimensional function that describes the vertical grain distribution within any longitudinal cross-section of the material layer. The model is based on a stochastic approach in combination with the convection-diffusion model from Meinel and Schubert (1971), expanded by Beck (1996), describing physical processes involved in grain penetrating the MOG layer. An analytical model for the grain movement on an oscillating cleaning shoe is given by Freye (1980). Several mathematical models using empirical, statistical and physical approaches have been developed in the last decades. As a result, a more physical insight in the cleaning process can be gained by interpreting these physical and statistical models. The developed models can also be seen as a tool for designers and researchers, who want to simulate and optimise the process. A disadvantage is that the coefficients in these mathematical functions are influenced by crop properties, adjustment and design parameters (Kutzbach, 2003).

Previous research, as mentioned above, tried to create a deeper insight in certain aspects of the cleaning section. However, a total mathematical model applicable to the cleaning process, which includes equations that describe (1) aerodynamic separation by the fan; (2) movement of the grain on the sieve section by the oscillating behaviour of the cleaning section; (3) movement of the grain through the mat due to gravity and resistive forces caused by the chaff and straw mat; (4) escape of the grain through the sieve opening based on probability theory, is not available and would be of high complexity.

Therefore, in this study, a test machine was equipped with a wide range of extra sensors in order to model the cleaning unit on a data-based manner. In part I of this study, a nonlinear genetic polynomial regression technique was proposed to rank the candidate input variables as possible regression variables for the prediction of the sieve losses. In this second part, the same input selection methodology is used to select the key input variables in order to predict the MOG in the grain bin.

No recent literature is available that discusses the impact of the settings of the cleaning section, like e.g. fan speed, lower sieve opening and upper sieve opening, on the MOG content in the grain bin, which is, however, an important performance parameter of the cleaning shoe. A prediction model for the MOG content in the grain bin could be of importance within the scope of automating the cleaning shoe.

\section{Materials and methods}

\subsection{Sensors for the combine harvesting process}

The working process of a combine harvester can be divided into four different sub-processes: (1) cutting of the crop and collection of the harvested material from the field; (2) the threshing process: the separation of grain kernels from larger crop parts such as straw; (3) the cleaning process: separating grain kernels from other small particles such as chaff and short straw; and (4) the temporary storage of clean grain materials in the grain bin.

The combine harvesting process is a highly uncertain process asking for sensors that extract immediate information from the process. Different measurement devices were installed on a New Holland CX test combine to extract information from the combine harvesting process, which could be valuable for automation. These sensors, listed in Table 1, either monitor the machine settings (driving speed, fan speed, upper and lower sieve opening), the machine load (feed-rate, torque drum, engine load, grain mass flow, sieve pressures (their configuration is shown in Fig. 1), return impact and return mass flow) or the field-related parameters (moisture content of the grain, lateral and longitudinal inclination). The signals of all these different sensors were logged during field experiments by means of a CANbus Control Design Interface program (Craessaerts et al., 2005). To determine the MOG content in the grain bin, grain coming out of the clean grain auger was manually collected in a bag at the grain tank. The grain bag samples are cleaned by a small cleaning unit and by consequence divided into a MOG and clean grain fraction. Afterwards, the different fractions are weighed.

\subsection{Input selection methodologies for linear and non- linear identification}

As mentioned earlier, several sensors were mounted on a test combine in order to give quantitative information about the combine harvesting process. Some of them contain valuable information while others do not. The purpose of introducing a variable selection technique at this stage of the research is to select the input variables that are most predictive of a given outcome. A non-linear genetic polynomial input selection methodology is proposed to select those measurement variables that have a significant impact on the MOG mass content percentage in the grain bin. The working principle and a statistical interpretation of the results of this genetic polynomial input selection methodology can be found in Craessaerts et al. (2007). 


\section{Table 1 - Overview of the different sensors used in this study}

\begin{tabular}{|c|c|}
\hline Sensor & Measurement principle \\
\hline Machine speed & An inductive sensor measures the rotation speed of the driving wheels as an estimation of the ground speed \\
\hline $\begin{array}{l}\text { Lower and upper sieve } \\
\text { opening }\end{array}$ & These settings are automatically set by an actuator, whose position is registered \\
\hline Fan speed & Rotation speed of the blower is measured by an rpm sensor \\
\hline Feedrate sensor & Measures the driving torque of the header as a measure of total crop inflow \\
\hline Torque drum & Measures the driving torque of the threshing drum \\
\hline Engine load & The load is estimated from the instantaneous fuel consumption \\
\hline Grain mass flow & Total amount of grain mass flow is measured at the end of the clean grain elevator \\
\hline Pressure sensors & $\begin{array}{l}\text { Two pitot pressure tubes and two differential pressure sensors (which measure the difference between static } \\
\text { and dynamic pressure) were placed near the exhaust of the blower. In addition, four differential pressure } \\
\text { sensors were equally distributed under the upper sieve (Fig. 1). }\end{array}$ \\
\hline Return impact sensor & Two impact sensors to detect the amount of grain kernels in the return flow \\
\hline Return mass flow & $\begin{array}{c}\text { The return mass flow is estimated by measuring the phase shift between two impeller blades of the return flow } \\
\text { transport. One of these is rigidly fixed while the other one is flexibly mounted }\end{array}$ \\
\hline Moisture & A capacitive sensor in the clean grain elevator measures the moisture content of the grain flow \\
\hline $\begin{array}{l}\text { Lateral and longitudinal } \\
\text { inclination }\end{array}$ & Two inclinometers are installed at the bottom of the machine \\
\hline
\end{tabular}

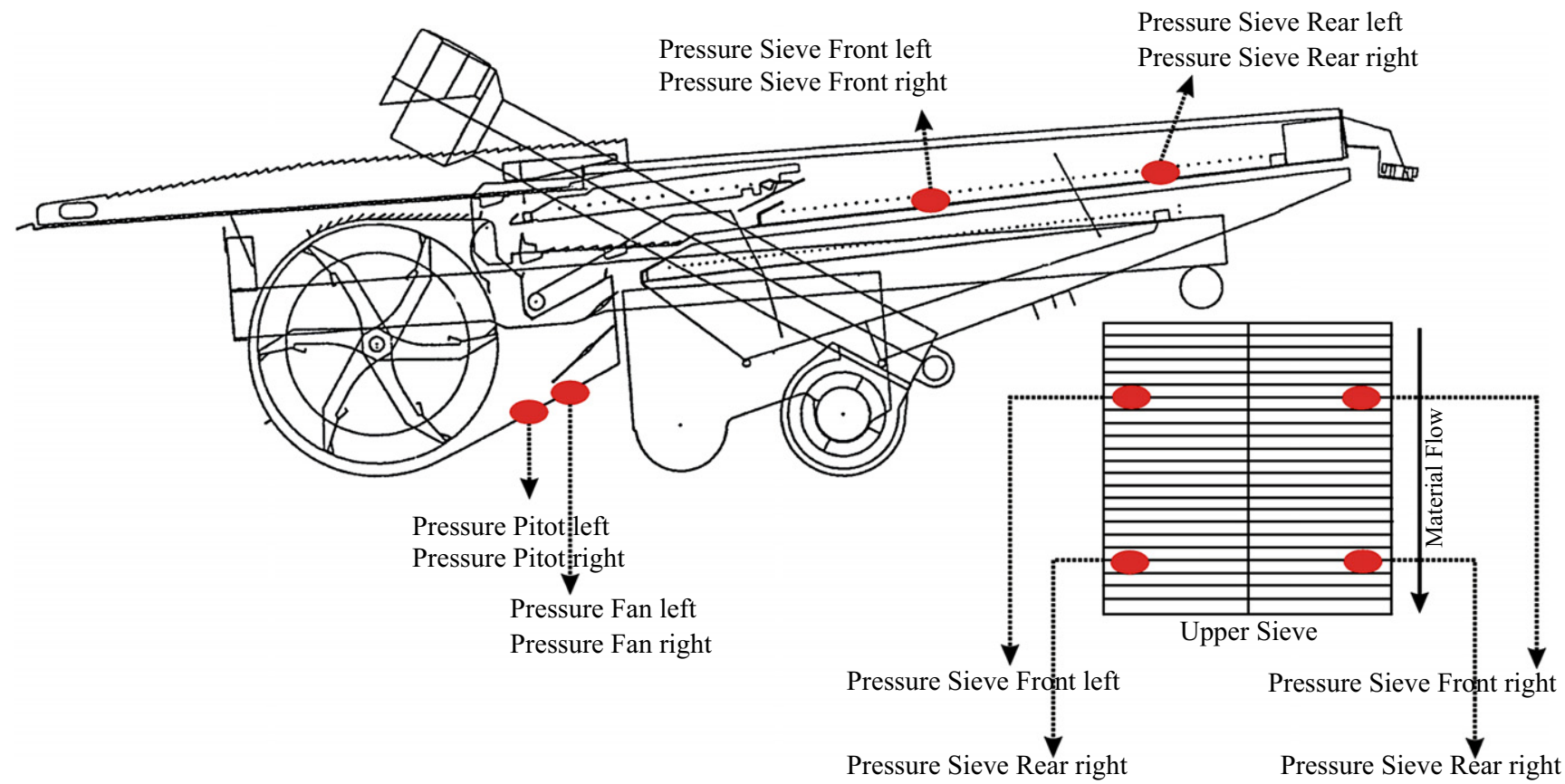

Fig. 1 - Configuration of the eight pressure sensors on the cleaning section of a combine harvester with their corresponding names.

\subsection{Test set-up}

During the summer of 2005, two different wheat fields of, respectively, 12 and 8 ha were harvested with a New Holland CX combine harvester. The test field was divided into different lines/runs of approximately 200-300 m length. Each line was harvested with a specific combination of machine settings (lower sieve opening, upper sieve opening and fan speed). Machine speed was kept constant at $4 \mathrm{~km} / \mathrm{h}$, but mainly due to variations in crop density, variations in incoming biomass may have occurred. An overview of the

Table 2 - Overview of the different machine settings during wheat harvest (2005)

\begin{tabular}{lccc}
\hline Machine Setting & Minimum & Maximum & Interval \\
\hline $\begin{array}{l}\text { Lower sieve opening } \\
\text { (mm) }\end{array}$ & 5 & 11 & 2 \\
$\begin{array}{l}\text { Upper sieve opening } \\
\text { (mm) }\end{array}$ & 11 & 19 & 2 \\
Fan speed (rpm) & 600 & 900 & 150 \\
\hline
\end{tabular}


range and intervals for the different machine settings is given in Table 2.

The machine behaviour was registered for each of the 60 possible machine setting combinations. Data collection was started approximately $30 \mathrm{~s}$. after the biological material entered the machine. This corresponds to the moment when the harvesting process reaches steady state. At the pre-processing stage of the data, an average of each signal was taken for each stationary run, because the corresponding signals remain more or less constant during these stationary runs. Table 3 gives an overview of the main signals that were registered at $5 \mathrm{~Hz}$ to monitor the cleaning process, together with their symbolic notation.

\section{Results and discussion}

\subsection{Pre-processing of the pressure signals}

In Craessaerts et al. (2007), a correction algorithm is proposed to make the standard pressure signals (X8-X15), as mentioned in Table 3, independent of the settings of the cleaning shoe (like fan speed, lower and upper sieve opening).

Table 3 - Overview of the measurement signals that are related to the cleaning process on a conventional combine harvester and their symbolic notation

\begin{tabular}{lc}
\hline Signal (unit) & Variable \\
\hline Feedrate (V) & $\mathrm{X} 1$ \\
Longitudinal inclination ( $\left.{ }^{\circ}\right)$ & $\mathrm{X} 2$ \\
Lateral inclination ( ${ }^{\circ}$ & $\mathrm{X} 3$ \\
Grain mass flow (ton/h) & $\mathrm{X} 4$ \\
Moisture (\%) & $\mathrm{X} 5$ \\
Ground speed (km/h) & $\mathrm{X} 6$ \\
Torque drum (V) & $\mathrm{X} 7$ \\
Pressure sieve front left (V) & $\mathrm{X} 8$ \\
Pressure sieve front right (V) & $\mathrm{X} 9$ \\
Pressure sieve rear left (V) & $\mathrm{X} 10$ \\
Pressure sieve rear right (V) & $\mathrm{X} 11$ \\
Pressure fan left (V) & $\mathrm{X} 12$ \\
Pressure fan right (V) & $\mathrm{X} 13$ \\
Pitot left (V) & $\mathrm{X} 14$ \\
Pitot right (V) & $\mathrm{X} 15$ \\
Return mass flow (V) & $\mathrm{X} 16$ \\
Return impact left (\#/200 ms) & $\mathrm{X} 17$ \\
Return impact right (\#/200 ms) & $\mathrm{X} 18$ \\
Lower sieve opening (mm) & $\mathrm{X} 19$ \\
Upper sieve opening (mm) & $\mathrm{X} 20$ \\
Fan speed (rpm) & $\mathrm{X} 21$ \\
Engine load (\%) & $\mathrm{X} 22$ \\
Pressure sieve front left (corrected) & $\mathrm{X} 23$ \\
Pressure sieve front right (corrected) & $\mathrm{X} 24$ \\
Pressure sieve rear left (corrected) & $\mathrm{X} 25$ \\
Pressure sieve rear right (corrected) & $\mathrm{X} 26$ \\
Pressure fan left (corrected) & $\mathrm{X} 27$ \\
Pressure fan right (corrected) & $\mathrm{X} 28$ \\
Pressure pitot left (corrected) & $\mathrm{X} 29$ \\
Pressure pitot right (corrected) & $\mathrm{X} 30$ \\
& \\
\hline & \\
&
\end{tabular}

As a result, the corrected pressure signals (X23-X30) are developed, which are a measure of the loadings by chaff, straw and grain on the upper sieve.

\subsection{Selection of regression variables for identification of the cleaning section}

All potential variables of Table 3 affect the cleaning process in one way or another. The key variables to build a nonlinear model were selected by making use of the genetic polynomial input selection algorithm as described in Craessaerts et al. (2007). The final results of an evolutionary input selection methodology are influenced by non-deterministic selection and combination methods, like cross-over, mutation, selection of initial population, etc. To minimise the impact of these random effects, the evolutionary selection procedure should be repeated a number of times. The results of 100 selection runs on the whole data set are presented in Fig. 2.

Based on the results in Fig. 2(a) the optimum number of input variables, could not be determined, since there is no decrease or increase in, respectively, the $R_{\text {adj }}^{2}$ or Mallows $C_{p}$ coefficient with an increasing number of regression variables. Nevertheless, it can be seen that the $R_{a d j}^{2}$ values do not increase significantly for a rising number of regression variables when the non-linear model consists of more than 3 different regression variables, such that 3 variables can be considered as a maximum. The best model structures, based on the $R_{\text {adj }}^{2}$ criterion, with 1-3 different regression variables are listed in Table 4 and are highly non-linear. It should be noted that the $R_{\text {adj }}^{2}$ values are calculated on the whole dataset. The results of the $R_{a d j}^{2}$ criterion are confirmed by the chance of appearance in the last-generation criterion [Fig. 2(c)] and the average elimination round criterion [Fig. 2(b)]. These criteria both point out the same key input variables: pressure sieve rear left (corrected) (X25), pressure pitot right (corrected) (X30) and lower sieve opening (X19). These results also show the importance of other corrected pressure signals like pressure sieve front left (corrected) (X23) and pressure fan right (corrected) (X28).

\section{Conclusions}

In this study, a first step towards a multivariate identification and control of the cleaning section of a combine harvester was investigated. A test combine was equipped with extra non-commercially available sensors in order to extract information about the cleaning section performance. Based on experimental data obtained during wheat harvest in 2005 and by making use of a genetic polynomial input selection algorithm, the most important sensors for a MOG prediction model were selected. It was found that the MOG content in the grain bin is affected in a non-linear manner by differences in the amount of biomass on the upper sieve and the fan speed, which are correlated with each other. It should be noted, however, that changes in biological (grain variety, moisture content) and/or environmental (slope) conditions 

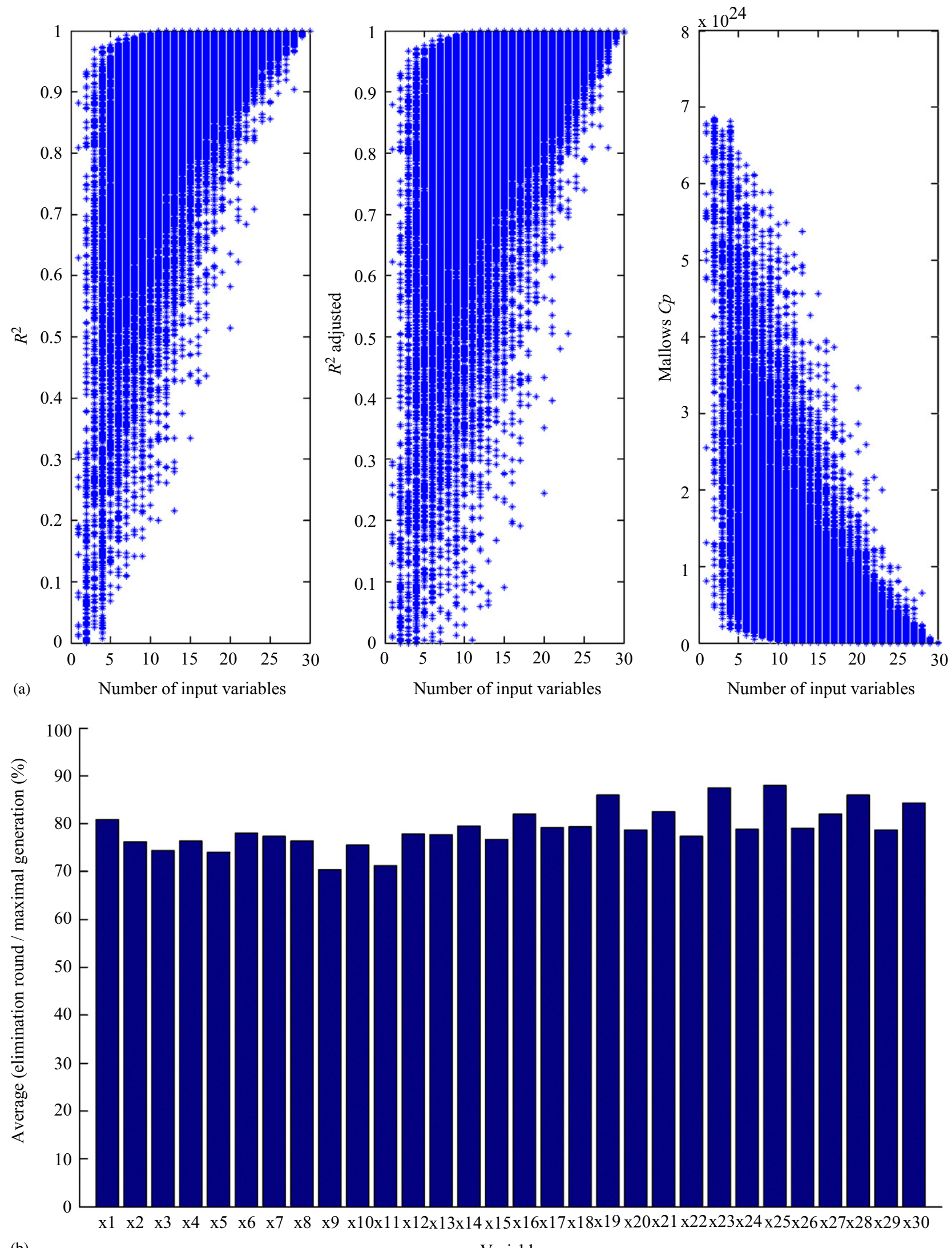

(b)

Variable

Fig. 2 - Results of the genetic polynomial input selection methodology: (a) Evaluation of the different model structures generated by the genetic polynomial regression technique with a variable number of input variables. Evaluation is based on $R^{2}, R_{a d j}^{2}$ and Mallows $C_{p}$ coefficients. (b) Average elimination round of the set of possible regressor variables. (c) Chance on appearance of the set of possible regressor variables in the last generation. 


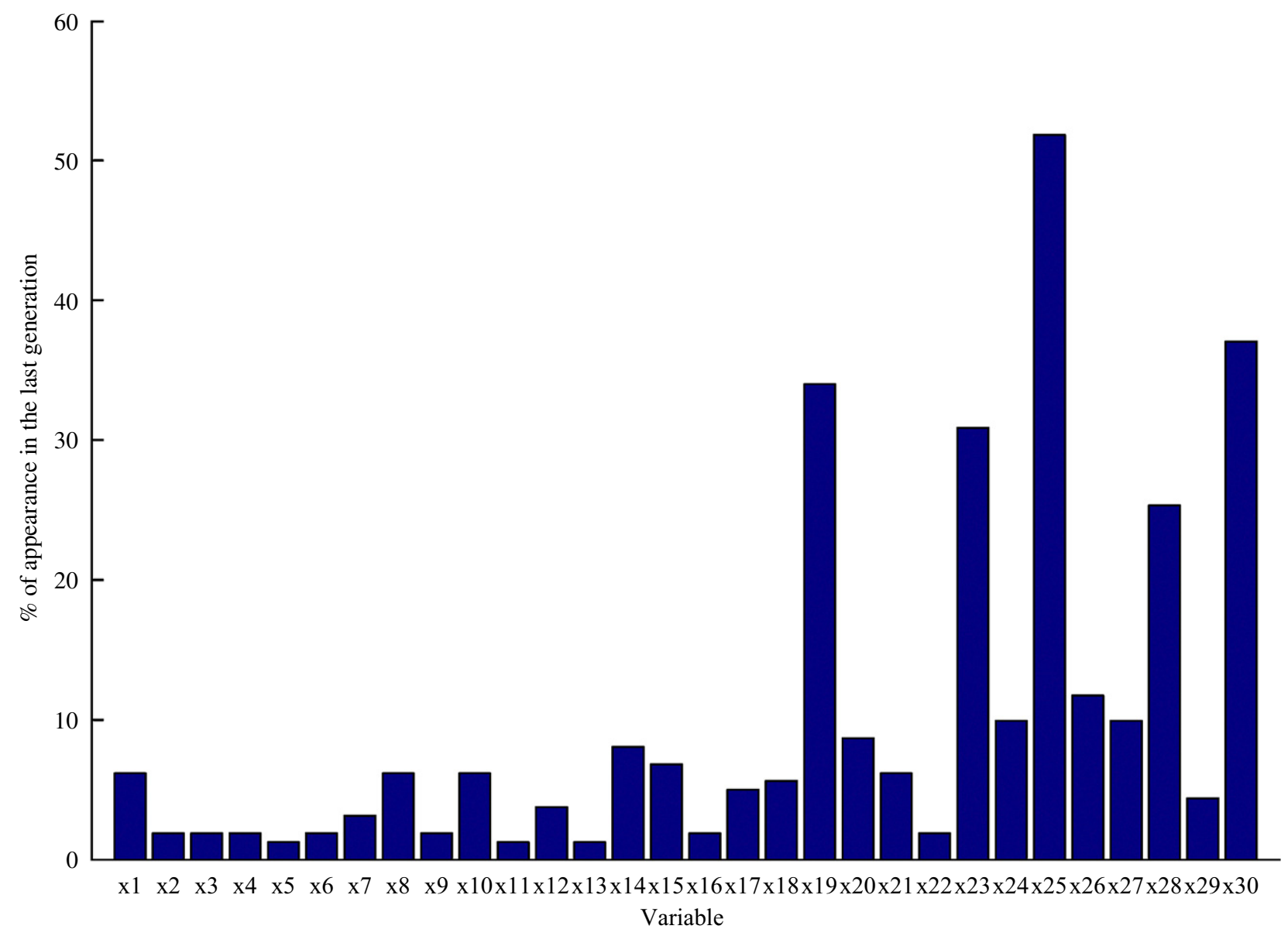

Fig. 2 - (Continued)

\section{Table 4 - Overview of the best model structures for the whole data set based on the $R_{a d j}^{2}$ criterion with a varying number of input variables}

\begin{tabular}{|c|c|c|}
\hline $\begin{array}{l}\text { No. input } \\
\text { variables }\end{array}$ & Best model structures based on $R_{\text {adj }}^{2}$ & $R_{a d j}^{2}$ \\
\hline 1 & $\begin{array}{c}Y=(a \times \text { pressure sieve rear left } \\
\text { (corrected) })\end{array}$ & 0.88 \\
\hline 2 & $\begin{array}{c}\mathrm{Y}=(a \times \text { pressure sieve rear left } \\
\left.(\text { corrected })^{2}\right)+(b \times \text { fan } \\
\left.\text { speed }^{2}\right)+(c \times \text { pressure sieve rear left } \\
(\text { corrected }) \times \text { fan speed }))\end{array}$ & 0.93 \\
\hline 3 & $\begin{array}{c}\mathrm{Y}=(a \times \text { pressure sieve rear left } \\
\left.(\text { corrected })^{2}\right)+(b \times \text { pitot left } \times \text { pressure } \\
\text { sieve rear left (corrected) })+(c \times \text { lower } \\
\text { sieve opening } \times \text { pressure sieve rear left } \\
(\text { corrected }))\end{array}$ & 0.96 \\
\hline
\end{tabular}

could indicate slightly different key input variables. In future, the data set will be extended for a wider range of conditions. Also, in a following study, non-linear fuzzy modelling techniques will be used to build a MOG prediction model using the indicative sensor signals selected in this study.

\section{Acknowledgements}

The authors gratefully acknowledge the I.W.T. (Instituut voor Wetenschappelijk Technologisch onderzoek) for the financial support and CNH Belgium for its cooperation. Wouter Saeys is funded as a Postdoctoral Fellow of the Research Foundation-Flanders (FWO).

R E F E R E N C E S

Beck F; (1996). Simulation der Trennprozesse im Mahdrescher (Simulation of Seperation processes in combine harvester). PhD Thesis, Vol. 14 (92), Fortschritt-Berichte VDI

Böttinger S; Kutzbach H D (1987). Performance characteristics of a cleaning unit under various crop conditions. ASAE Paper No. 87-1512

Craessaerts G; Maertens K; De Baerdemaeker J (2005). A design environment for combine automation via CANbus. Computers and Electronics in Agriculture, 49(2), 233-245

Craessaerts G; Saeys W; Missotten B; De Baerdemaeker J (2007). A genetic input selection methodology for identification of the cleaning process on a combine harvester, part I: selection of 
relevant input variables for identification of the sieve losses. Biosystems Engineering, (2007), doi:10.1016/j.biosystemseng. 2007.07.002.

Freye T (1980). Untersuchungen zur trennung von korn-spreugemischen durch die reinigungsanlage des mähdreschers. Forschungsbericht Agrartechnik der Max-Eyth-Gesellschaft (MEG). Dissertation, Hohenheim

Hubner R (1997). Entwicklung eines modells zur auslegung einer rotierenden reinigungseinrichtung im mähdrescher. Dissertation, TU Dresden

Kutzbach H D (2003). Approaches for mathematical modelling of grain separation. Proceedings of the International Conference on Crop Harvesting and Processing. ASAE Publication No.

701P1103e
Meinel A; Schubert H (1971). Zu der grundlagen der Feinsiebung (On fundamentals of fine screening). Aufbereitungstechnik, 12(3), 128-133

Miu P I (2003) Stochastic modeling of separation process on combine cleaning shoe. Proceedings of the International Conference on Crop Harvesting and Processing. ASAE Publication No. 701P1103e

Rothaug S; Wacker P; Yin W; Kutzbach H D (2003). Capacity increase of cleaning units by circular oscillation. Proceedings of the International Conference on Crop Harvesting and Processing, ASAE Publication No. 701P1103e

Srivastava A K; Goering C E; Rohrbach R P; Buckmaster D R (2006). Engineering Principles of Agricultural Machines. American Society of Agricultural and Biological Engineers (ASAE) St Joseph, MI, USA 